\title{
Knowledge and Attitude on Pain Management among Final Year Nursing and Midwifery Students of Khesar Gyalpo University of Medical Sciences of Bhutan
}

\author{
Kuenzang $^{1}$, Hari Prasad Pokhrel ${ }^{* 2}$, Passang Lhamo Sherpa ${ }^{3}$ \\ ${ }^{1}$ Dewathang Hospital, Samdrup Jongkhar, Bhutan \\ ${ }^{2}$ Samdrup Jongkhar General Hospital, Samdrup Jongkhar, Bhutan \\ ${ }^{3}$ Faculty of Nursing and Public Health, KGUMSB, Thimphu Bhutan
}

Corresponding author

Hari Prasad Pokhrel

Sr. Nutritionist, Samdrup Jongkhar General Hospital, Bhutan

Email id: hari88pokhrel@gmail.com

Contact number: 00975-17492684

\begin{abstract}
Pain management is the most important component of nursing care process and it is crucial for nurses to have a good level of knowledge on pain management. A cross-sectional study was conducted among 44 final year General Nursing and Midwifery students at the Faculty of Nursing and Public Health, Khesar Gyalpo University of Medical Sciences of Bhutan in May 2016. Independent samples T- test was used to assess the association. The mean (SD) age of the respondents was 22.66 years (1.26). Over two-thirds (81.8\%) of the participants had a poor level of knowledge and a majority $(90.9 \%)$ of them had never been posted to a pain clinic. Over a half of them (56.8\%) had negative attitude towards pain management. Independent samples t-test detected a significant difference in the mean knowledge scores between students who regularly used pain assessment scales and those who did not use the scales respectively. The study recommends to include pain management as a standalone module to better equip the nurses with knowledge on pain management. Mandatory posting of the students in pain clinic will provide the students with an opportunity to practice the skills.
\end{abstract}

Keywords: Knowledge and attitude; pain management; Nursing and Midwifery students; Bhutan.

\section{Introduction}

"Pain is an unpleasant sensory and emotional experience associated with actual or potential tissue damage, or described in terms of such damage" as defined by the International Association for the study of pain. ${ }^{[1]}$ Acute or chronic pain due to injury, illness, therapeutic treatment and surgery have become a massive public health concern to millions of people annually. ${ }^{[2,3]}$ Pain is the most common reason for seeking healthcare services but is often left untreated. ${ }^{[2]}$ Patients have the right to seek health care services and nurses should give the highest priority to ease them of their discomfort. ${ }^{[4]}$ Among the health care team, nurses play a major role in pain management and are primarily responsible to execute an accurate assessment, evaluate and intervene to relieve pain and to provide comfort during hospitalization. ${ }^{[2-4]}$ Nurses spend their maximum time with patient while carrying out the nursing care plan, assessing and re-assessing pain, identifying problems, implementing treatment plans, interacting and advocating health education. These are significant components of best practices of pain management during the nursing processes. ${ }^{[4-6]}$ While it is indispensable that nurses require a comprehensive knowledge and effective communication, ${ }^{[4,7]}$ several studies have documented an inadequacy of knowledge and attitude towards pain management among nursing students. ${ }^{[4,7-9]}$ Pain assessment is now recorded as the fifth vital sign of the patient and is required to be taught to nursing students at the beginning of their clinical education as a standalone topic and not as parts of other topics. ${ }^{[10]}$ This is because assessing and managing pain is complex as it largely relies on subjective accounts, patient expectation and assessor's knowledge of pain management rather than on objective data as in other vital signs. ${ }^{[10]}$

A Master thesis conducted in 2004 documented inadequate knowledge on pain management among Bhutanese nurses. The study also reported that pain management components were inadequately covered in the nursing educational curriculum and recommended a comprehensive coverage. ${ }^{[11]}$ Although there are few studies on knowledge and attitude of nurses towards pain management, literature on knowledge and attitude of nursing students in Bhutan could not be found. Thus, this study explored the knowledge and attitude towards pain management among final year nursing students of the FNPH, KGUMSB. 


\section{Methodology}

A cross-sectional study was conducted among final year General Nursing and Midwifery (GNM) students at the Faculty of Nursing and Public Health (FNPH), Khesar Gyalpo University of Medical Sciences of Bhutan (KGUMSB). The research instrument was adapted from Nurses' Attitude Survey (NAS) by McMillan and Tittle (2000) and Knowledge and Attitude Survey Regarding Pain (KARSP) by Ferrell \& McCaffery, (2012) to fit the local context. Questions were grouped into five categories comprising of pain assessment, intervention, medication, pathophysiology and addiction. The research instrument was then validated by lecturers of FNHP. The validation team comprised of a medical doctor teaching at the department of public health and allied sciences and two lecturers who teach medical-surgical nursing. The questions were marked as 'appropriate', 'uncertain' or 'inappropriate' by the validation team. The questionnaire was piloted among second year GNM students studying at the same institute. Reliability test of the questionnaire showed that Cronbach's alpha coefficient was 0.73 . Knowledge was assessed using 20 questions and classified as 'good', 'moderate' and 'poor' using Benjamin Bloom classification of cognitive skills while attitude towards pain management was assessed using 10 statements and scored on a five point Likert scale and classified as positive and negative perception based on

Table 1: General Characteristics $(n=44)$

\begin{tabular}{lrrr}
\hline \multicolumn{2}{ll}{ Characteristics } & Number & Percent \\
\hline Age & $20-22$ & & \\
\\
$23-26$ & 18 & 26 & 40.9 \\
\end{tabular}

Mean 22.66, SD 1.26

Gender

Female 23

Male 21

52.3

21

47.7

Read books or journals on pain management

Yes

No

Regular use of pain assessment scales

Yes

No

20

Type of scales used

Numerical rating scale

Wong-Barker faces pain rating scale

Visual analog scale

More than 1 scale

Ever posted in Pain clinic

Yes

No

Level of Knowledge

Good (16-20 scores)

Moderate (12 -15 Scores)

07

Poor (0 -11 scores)

Median score 9, Minimum 5, Maximum 16

Attitude to Pain management 
Mean knowledge and attitude score among different categories were compared by independent sample T-test. There was a significant difference in mean knowledge score among participants who made regular use of pain measurement scale compared to those who did not use the scale (table 2).

Table 2: Independent samples $\mathbf{T}$ test

\begin{tabular}{|c|c|c|c|c|c|}
\hline Characteristics & $\mathbf{n}$ & Mean & SD & mean difference & p-value \\
\hline \multicolumn{6}{|c|}{ Knowledge } \\
\hline \multicolumn{6}{|l|}{ Gender } \\
\hline Male & 21 & 9.90 & 2.406 & -0.052 & 0.943 \\
\hline Female & 23 & 9.96 & 2.364 & & \\
\hline \multicolumn{6}{|c|}{ Read books or journals on pain management } \\
\hline Yes & 20 & 10.15 & 2.455 & 0.400 & 0.581 \\
\hline No & 24 & 09.75 & 2.308 & & \\
\hline \multicolumn{6}{|c|}{ Regular use of pain assessment scales } \\
\hline Yes & 20 & 9.10 & 1.889 & -1.525 & $0.031^{*}$ \\
\hline No & 24 & 10.63 & 2.516 & & \\
\hline \multicolumn{6}{|l|}{ Attitude } \\
\hline Negative & 25 & 9.44 & 2.123 & -1.139 & 0.113 \\
\hline Positive & 19 & 10.58 & 2.545 & & \\
\hline \multicolumn{6}{|c|}{ Attitude } \\
\hline \multicolumn{6}{|l|}{ Gender } \\
\hline Male & 21 & 30.62 & 3.008 & 1.358 & 0.151 \\
\hline Female & 23 & 29.26 & 3.137 & & \\
\hline \multicolumn{6}{|c|}{ Read books or journals on pain management } \\
\hline Yes & 20 & 29.65 & 3.360 & -0.475 & 0.620 \\
\hline No & 24 & 30.13 & 2.953 & & \\
\hline \multicolumn{6}{|c|}{ Regular use of pain assessment scale } \\
\hline Yes & 20 & 29.20 & 2.726 & -1.300 & 0.171 \\
\hline No & 24 & 30.50 & 3.349 & & \\
\hline \multicolumn{6}{|l|}{ Knowledge } \\
\hline Poor & 36 & 29.61 & 2.861 & -1.639 & 0.182 \\
\hline Moderate-Good & 8 & 31.25 & 4.027 & & \\
\hline
\end{tabular}

*significant at p-value $<0.05$.

\section{Discussion}

The study found that majority of the students had a poor level of knowledge while over a half of them had a negative attitude towards pain management. This might be because pain management is taught at the FNPH as a part of medical-surgical disease condition and not as a separate module. Assessing pain is a challenging activity and requires comprehensive knowledge and skills as well as positive attitude. ${ }^{[12]}$ Accurate assessments and good documentations are essential for effective pain management. ${ }^{[13,14]}$ However, many studies have documented an inadequacy of knowledge and attitudes towards pain management. ${ }^{[2,7-9]}$

Independent samples T-test showed that students who did not regularly use pain assessment scales had a significantly higher mean knowledge scores compared to those who used the scales. This could be possible because students used these scales despite their limited knowledge and practice. A study conducted in Jordan among nursing students reported that regular usage of pain assessment tool is difficult due to lack of training. ${ }^{[9]}$ Although there appears to be a system of posting the students to pain clinic, majority of them had never been posted there for hands-on practice and skill enhancement which suggests that the posting was not mandatory. It is often difficult to determine how much time the students spend in understanding pain management. The study found that less than half of the students read books or articles on pain management. A study conducted in Jordan reported that only around $45.8 \%$ of the nursing students read books or journals on pain management. ${ }^{[7]}$ while a study conducted among the nursing professionals at Cukurova University Hospital in Turkey found that less than $15 \%$ of the participants read journal on pain. ${ }^{[15]}$ A study conducted in England reported that pain management aspects are superficially covered and suggested re-evaluation of the module. ${ }^{[5]}$

This study had a small sample size $(n=44)$ which was also the total population of the final year GNM students at the faculty. The findings may not be generalizable to nursing professionals who studied in other institutes both in Bhutan and other countries. However, FNPH is the oldest and was the only nursing education institute until 2016, thus, a vast majority of the nursing professionals in Bhutan are alumni of this faculty. Therefore, the findings can be generalized to a large proportion of practicing nurses in Bhutan. 


\section{Conclusion}

Students had a poor level of knowledge on pain management and a majority of them had never been posted to a pain clinic. Over a half of them had a negative attitude towards pain management. The study recommends that pain management be taught as a standalone module and not as part of other modules/chapters. Mandatory posting of the students in pain clinic will provide the students with hands-on opportunity to practice and enhance their skills.

\section{Acknowledgements}

The authors would like to thank the Faculty of Public Health, Khesar Gyalpo University of Medical Sciences of Bhutan for permitting us to conduct this study. In equal measure we would like to thank all the participants for their time.

\section{Funding}

No funding was required for the conduct of this study.

\section{Conflict of Interest}

The authors have no conflict of interest to declare.

\section{References}

[1] International association for the study of pain: Pain term. $2014 . \quad \mathrm{http} / / / \mathrm{www} \cdot$ lasppain.org/Education/Content.aspx?ItemNumber=1698\#pai n. Accessed 06/04/2018.

[2] Ersek M, Polomano RC. Pain. In: Lewis SR, Dirsen MN, Heitkemper LB, Camera IM, editors. Medical surgical nursing-assessment and management of clinical problems 8ed. USA: Medical surgical nursingassessment and management of clinical problems 2011.

[3] Goldberg DS, McGee SJ. Pain as a global public health priority. BMC Public Health. 2011;11:1-5.

[4] Plaisance L, Logan C. Nursing students' knowledge and attitudes regarding pain. Pain Manag Nurs. 2006;7(4):167-75.
[5] Twycross A. Education about pain: a neglected area? Nurse Educ Today. 2000;20:244-53.

[6] Brown MA. The role of nurses in pain and palliative care. J Pain Pallait Care Pharmacother. 2013;27:300-2.

[7] Al-Khawaldeh OA, Al-Hussami M, Darawad M. Knowledge and attitudes regarding pain management among Jordanian nursing students. Nurse Educ Today. 2013;33:339-45.

[8] Chow KM, Chan JC. Pain knowledge and attitudes of nursing students: a literature review. Nurse Educ Today. 2015;35.

[9] Al-Khalaileh M, Al-Qadire M. Pain management in Jordon: nursing students' knowledge and attitude. $\mathrm{Br} \mathrm{J}$ Nurs. 2013;22(21).

[10] Morone NE, Weiner DK. Pain as the fifth vital sign: exposing the vital need for pain education. Clin Ther. 2013;35(11):1728-32.

[11] Wangmo D. Barriers to effective pain management in adult patient in Bhutan: Prince of Songkla University; 2004.

[12] Tse MMY, Ho SSK. Enhancing knowledge and attitudes in pain management: a pain management education program for nursing home staff. Pain Manag Nurs. 2014;15(1):2-11.

[13] Song W, Eaton LH, Gordon DB, Hoyle C, Doorenbos AZ. Evaluation of Evidence-Based Nursing Pain Management Practice. Pain Manag Nurs. 2014;16 (4):456-63.

[14] Torvik K, Nordtug B, Brenne IK, Rognstad M-K. Pain Assessment Strategies in Home Care and Nursing Homes in Mid-Norway: A Cross-sectional Survey. Pain Manag Nurs. 2015;16(4):602-8.

[15] Akbas M, Öztunç G. Examination of knowledge about and nursing interventions for the care of patients in pain of nurses who work at Cukurova University medical faculty Balcali hospital. Pain Manag Nurs. 2008;9(3):8895. 